\title{
Catalytic transesterification of $\beta$-ketoesters with zeolite H-FER under solvent free conditions
}

\author{
Subhash P. Chavan, ${ }^{\text {a }}$ K. Pasupathy, ${ }^{\text {a Sudhir Shengule, }}$, \\ Vikas Shinde, ${ }^{a}$ and R. Anand ${ }^{b}$ \\ ${ }^{a}$ Organic Chemistry: Technology Division, National Chemical Laboratory, Pune 411008, India \\ ${ }^{b}$ Catalysis Division, National Chemical Laboratory, Pune 411008, India \\ E-mail: spchavan@dalton.ncl.res.in
}

(received 07 Dec 04; accepted 22 Apr 05; published on the web 07 May 05)

\begin{abstract}
Zeolite H-FER catalyzes the transesterification of $\beta$-ketoesters with variety of alcohols under solvent-less condition in excellent yields. The catalyst can be reused without any loss of activity.
\end{abstract}

Keywords: Transesterification, zeolite, ferrierite

\section{Introduction}

Organic reactions using conventional organic solvents especially chlorinated hydrocarbons have posed a serious threat to the environment owing to their toxicity and volatile nature. ${ }^{1}$ In this regard solvent free catalytic organic reaction has received tremendous attention in recent times. ${ }^{2}$ $\beta$-Ketoesters are popular synthons are classically prepared from the reaction of highly reactive ${ }^{3}$ and unstable diketene with various alcohols. Several diketene-free approaches particularly by transesterification of $\beta$-ketoesters to the preparation of $\beta$-ketoesters have been documented in the literature. $^{4,5}$ Since uncatalyzed transesterification of $\beta$-ketoesters, ${ }^{6,7}$ require use of either excess of $\beta$-ketoester or longer duration time and employ high boiling alcohols or utilize unconventional energy sources thus limiting their usage, protic acids, Lewis acids ${ }^{8}$ and basic catalysts ${ }^{9,10,11}$ have been reported to effectively catalyze the transesterification of $\beta$-ketoesters. Though there are several catalysts reported in the literature, they suffer from certain drawbacks, of being expensive or moisture sensitive and cannot be reused. Most of the protic acid catalysts are highly corrosive and are not ecofriendly. In this regard great deal of attention has been given to effect transesterification of methyl or ethyl acetoacetates using heterogeneous catalyst under mild conditions. We were the first to describe the utility of heterogeneous catalyst $\mathrm{S}_{-} \mathrm{SnO}_{2}{ }^{12}$ as an efficient catalyst in effecting transesterification. After our publication several other heterogeneous catalysts were also shown to be effective. ${ }^{13,14}$ We have also shown commercially available Amberlyst- $15^{15}$, zinc- $\mathrm{I}_{2}$ and $\mathrm{I}_{2}{ }^{16}$ to be an efficient catalyst for transesterification. 
Zeolites have been reported as catalysts for the transesterification of $\beta$-ketoesters employing toluene as the solvent. ${ }^{14}$ Thus as a part of our program towards green synthesis we have already reported acetylation of alcohols catalyzed by H-FER (medium pore zeolite) under solvent free condition. ${ }^{16}$ Zeolite Ferrierite, in its acidic form H-Ferrierite (H-FER), is an exceptionally selective and stable catalyst for the skeletal isomerisation of linear butanes to isobutene. ${ }^{17 c, 17 \mathrm{~d}}$ This manuscript describes an efficient method for transesterification of $\beta$-ketoesters catalyzed by hydrogen form of FER under solvent free condition (Scheme 1).<smiles>[R]OC(=O)CC(C)=O</smiles>

\section{Scheme 1}

\section{Results and Discussion}

In order to ascertain the role of H-FER as catalyst in enhancing the rate of the reaction, transesterification of cycloheptanol was conducted in the absence of H-FER. From Scheme 2 it is clear that the time taken for the reaction by employing H-FER as the catalyst is considerably reduced. A variety of $\beta$-ketoesters was treated with alcohols in the presence of H-FER as the catalyst to give the corresponding transesterified esters in good to excellent yields. The low boiling alcohol (methanol or ethanol) formed in the reaction was continuously removed by distillation. The results of this protocol are summarized in table 1 .
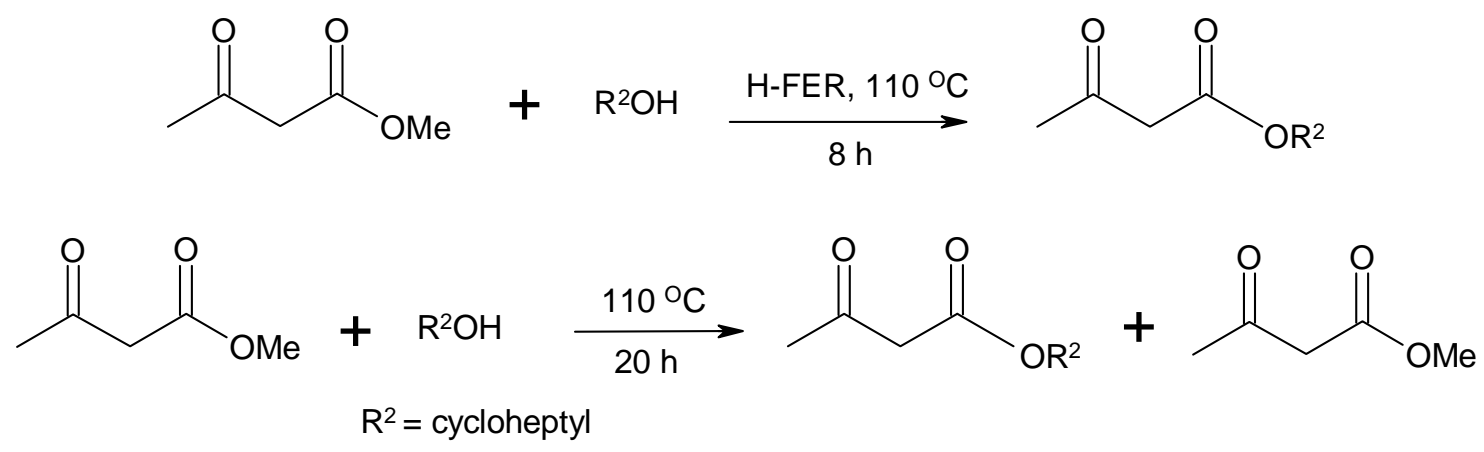

\section{Scheme 2}


Table 1

\begin{tabular}{|c|c|c|c|c|}
\hline Sr. No. & Ester(A) & Alcohol(B) & $\operatorname{Product}(\mathrm{C})$ & $\begin{array}{l}\% \text { Yield } \\
\text { (Isolated) }\end{array}$ \\
\hline 1 & & & & 72 \\
\hline 2 & & & & $90^{\mathrm{a}}$ \\
\hline 3 & & & & 61 \\
\hline 4 & & & & 85 \\
\hline 5 & & & & 90 \\
\hline 6 & & $\mathrm{OH}$ & & 65 \\
\hline 7 & & $\mathrm{OH}$ & & 84 \\
\hline 8 & & & & 70 \\
\hline 9 & & & & 71 \\
\hline 10 & & & & 80 \\
\hline
\end{tabular}


Table 1. Continued

11<smiles>COC(=O)CC(C)=O</smiles>

12<smiles>COC(=O)CC(C)=O</smiles>

13<smiles>COC(=O)CC(C)=O</smiles>

14<smiles>CCOC(=O)CC(=O)c1ccccc1</smiles>

15<smiles>CCOC(=O)C1CCCC1=O</smiles>

16<smiles>CCOC(=O)C1CCCC1=O</smiles><smiles>OC[13CH](O)CO</smiles><smiles>CC(=O)CC(=O)OCc1ccccc1</smiles>

${ }^{\mathrm{a}}[\alpha]_{\mathrm{D}}{ }^{25}-72.00(\mathrm{c}=10.24$, benzene $)$, lit. $^{6 \mathrm{~d}}[\alpha]_{\mathrm{D}}{ }^{25}-69.30(\mathrm{c}=10$, benzene $)$.

In most of the cases only 1.2 equivalents of alcohols were used. Only in case of volatile alcohols (Table 1, entries 3, 6, 7, 12 and 13) like propargyl alcohol, allyl alcohol, isobutanol, isopropanol, propanol, 2 equivalents of alcohol were used. A note worthy feature of the present protocol is that benzyl, allyl and propargyl esters (entries 3,6 and 10) become readily accessible. The allyl and propargylesters are known to be difficult to prepare as they readily undergo the Carrol rearrangement. ${ }^{18}$ It is evident from the table 1 that both the primary and secondary alcohols participate well in the reaction. However tertiary alcohol (tert-butanol) did not furnish the corresponding tert-butyl ester. Apart from methyl and ethyl acetoacetate, this synthetic methodology focuses on structurally varied beta-keto esters such as ethyl benzoylacetate ${ }^{19}$ (entry 14) and cyclopentanone keto ester (entry 15), which underwent smooth transesterification to provide the corresponding transesterified esters in good yields. Keto ester 14C exists as keto: enol tautomers in the ratio 3:1 ( ${ }^{1} \mathrm{H}$ NMR analysis). Substitution at the $\alpha$-position of $\beta$-ketoester was found to be detrimental for smooth transesterification. This was evident with the reaction of 2-methyl-3-oxo-butyric acid ethyl ester (entry 16) with benzyl alcohol even after $16 \mathrm{~h}$ reaction 
was found to be only $44 \%$ complete as per ${ }^{1} \mathrm{H}$ NMR analysis. Under similar conditions keto ester 6 (Scheme 3) failed to undergo transesterification suggests that the reaction proceeds via the activation of carbonyl groups of the $\beta$-ketoester leading to the formation of acyl ketene as proposed by Campbell and co-workers. $^{20}$

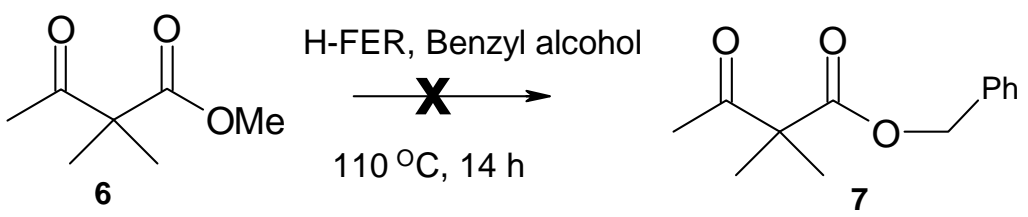

\section{Scheme 3}

It should be pointed out that phenol, p-cresol, m-chlorophenol failed to undergo transesterification. This zeolite was reused several times without any loss of activity by filtering the catalyst, washing with acetone, drying and reusing immediately.

In conclusion, the present protocol describes a simple and efficient method for the transesterification of $\beta$-ketoesters by different alcohols catalyzed by H-FER under solvent free condition. It has been demonstrated that transesterification of $\beta$-ketoesters with different alcohols proceeded with fairly high yields in a relatively short reaction time and avoids the use of aromatic solvents such as toluene and xylene that are usually employed. The obvious advantages of heterogeneous catalysis in terms of simple operation coupled with the ease of workup and recyclability of the catalyst without any loss of its activity are noteworthy. These conditions enable minimum waste and offer an environmentally benign protocol.

\section{Experimental Section}

General Procedures. The zeolite H-FER catalyst was synthesized according to the reported procedure. ${ }^{17 \mathrm{~b}}$ In a typical batch, $52.5 \mathrm{~g}$ of sodium silicate (in $25 \mathrm{ml}$ of distilled water) was stirred with $10 \mathrm{ml}$ pyrrolidine. To this solution, $2.4 \mathrm{~g}$ of aluminum sulfate hexadecahydrate (in $25 \mathrm{ml}$ distilled water) and $1.8 \mathrm{~g}$ of sulfuric acid (in $10 \mathrm{ml}$ distilled water) was added. Finally, $30 \mathrm{ml}$ of distilled water was added and the gel $(\mathrm{pH} 11.5 \pm 0.2)$ was stirred vigorously for $2 \mathrm{~h}$ and autoclaved in a $300 \mathrm{ml}$ stainless steel Parr autoclave $(4842,300 \mathrm{ml})$ and heated at $160{ }^{\circ} \mathrm{C}$ for 60 h. The initial gel composition was: $20 \mathrm{Na} 2 \mathrm{O}+\mathrm{Al}_{2} \mathrm{O}_{3}+37$ pyrrolidine $+66.5 \mathrm{SiO}_{2}+6.3 \mathrm{H}_{2} \mathrm{SO}_{4}$ $+1460 \mathrm{H}_{2} \mathrm{O}$. The autoclave was quenched and the product filtered off, washed and dried at $100{ }^{\circ} \mathrm{C}$ for $6-8 \mathrm{~h}$. The resulting material was calcined in air at $550{ }^{\circ} \mathrm{C}$ for $18-20 \mathrm{~h}$ and then exchanged with $1 \mathrm{M} \mathrm{NH}_{4} \mathrm{NO}_{3}$ solution three times, followed by calcination at $550{ }^{\circ} \mathrm{C}$ for $10 \mathrm{~h}$ to yield $\mathrm{H}$ FER zeolite. The catalyst was characterized by X-ray powder diffraction (Rigaku, D-Max III VC diffractometer with $\mathrm{Cu}-\mathrm{Ka}$ radiation, $1.5404 \AA$ ) for its phase purity. The chemical composition of silica and alumina was established by a wavelength dispersive XRF (3070 Rigaku) 
spectrophotometer. Thermogravimetric analysis (TGA) and differential thermal analysis (DTA) were carried out in flowing air at a heating rate of $10{ }^{\circ} \mathrm{C} / 21 \mathrm{~min}$ on an autonomic TG/DTA (SETRAM 92). An Omnisorp 100 CX (COULTIER Corporation, USA) analyzer was used for the measurement of low-pressure nitrogen adsorption to determine the surface area. The Lewis and Bronsted acidity of the H-FER catalyst sample was determined by adsorbing $\mathrm{CD}_{3} \mathrm{CN}$ on the catalyst wafer and then characterized by FTIR spectrometry (Nicolet Magne-550 FTIR).

\section{Typical procedure}

In a typical example, a mixture of ethyl benzoyl acetate (entry 14A, 10mmol), $p$-methoxybenzyl alcohol $(14 \mathrm{~B}, 12 \mathrm{mmol})$ and H-FER $(0.15 \mathrm{~g})$ was stirred at $110^{\circ} \mathrm{C}$ for $8 \mathrm{~h}$. After completion of the reaction (monitored by TLC), catalyst was removed by filtration and washed with ethyl acetate. The solvent was removed under reduced pressure to obtain the crude product $14 \mathrm{C}$ which was further purified by column chromatography on silica gel \{eluent: ethyl acetate: petroleum-ether $\left(\right.$ bp $\left.\left.40{ }^{\circ} \mathrm{C}-60{ }^{\circ} \mathrm{C}\right)=1: 9\right\}$.

3-Oxo-3-phenyl-propionic acid 4-methyoxy-benzyl ester (14C):

IR $\left(\mathrm{CHCl}_{3}\right) \mathrm{cm}^{-1}: 1740,1687 ;{ }^{1} \mathrm{H}-\mathrm{NMR}\left(200 \mathrm{MHz}, \mathrm{CDCl}_{3}+\mathrm{CCl}_{4}\right) \delta:[3.80,3.82(\mathrm{~s}, 3 \mathrm{H})],[4.00$, 5.70, $12.55(\mathrm{~s}, 2 \mathrm{H})],[5.13,5.19(\mathrm{~s}, 2 \mathrm{H})], 6.87(\mathrm{~m}, 2 \mathrm{H}), 7.33-7.55(\mathrm{~m}, 4 \mathrm{H}), 7.59(\mathrm{~m}, 1 \mathrm{H}), 7.77-$ $7.52(\mathrm{~m}, 2 \mathrm{H})$; Mass ESI (m/z): $285(\mathrm{M}+1)^{+}$.

All the $\beta$-ketoesters prepared in the present work are well known compounds and are easily identified by the IR, ${ }^{1} \mathrm{H}$ NMR and mass spectra in comparison with the reported data.

\section{Acknowledgements}

The authors K.P. and R.A. thank CSIR, New Delhi, India for financial assistantship. Funding by CSIR, New Delhi under the YSA (SPC) scheme is gratefully acknowledged.

\section{References}

1. Nelson, W. M. In Green Chemistry; Anastas, P. T.; Williamson, T. C., Eds; Oxford University Press: Oxford, 1998; Ch. 12, p 200

2. (a) Tanaka, K. Solvent Free Organic Synthesis; Wiley-VCH: New York, 2003. (b) Cave, G.; W. V.; Raston, C. L.; Scott, J. L. Chem. Commun. 2001, 2159. (c) Tanaka, K.; Toda, F. Chem. Rev. 2000, 100, 1025. (d) Metzger, J. O. Angew. Chem., Int. Ed. 1998, 37, 2975.

3. Clemens, R. J. Chem. Rev. 1986, 86, 241

4. (a) Hauser, C. R.; Hudson, B. E. Org. React. 1, 1942, 266. (b) Davis, B. R.; Garrett, P. J. Comp. Org. Syn. 2, 1991, 806. (c) Clemens, R. J.; Hyatt, J. A. J. Org. Chem. 1985, 50, 2431. (d) Brown, D. S.; Marples, B. A.; Smith, P.; Walton, L. Tetrahedron 1995, 51, 3587. 
(e) Oikawa, Y.; Sugano, K.; Yonemitsu, O. J. Org. Chem. 1978, 43, 2087. (f) Bandgar, B. P.; Pandit, S. S.; Sadavarte, V. S. Green Chem. 2001, 3, 247.

5. Otera, J. Chem. Rev. 1993, 93, 1449.

6. (a) Caroll, M. F.; Proc. XI Intern. Congr. Pure. Appl. Chem. 1947, 2, 39. (b) Bader, A. R.; Cumming, L. O.; Vogel, H. A. J. Am. Chem. Soc. 1951, 73, 4195. (c) Mottet, C.; Hamelin, O.; Garavel, G.; Depres, J.; Greene, A. E. J. Org. Chem. 1999, 64, 1380. (d) Gianotti, M.; Martelli, G.; Spunta, G.; Campana, E.; Panunzio, M.; Mendozza, M. Synth. Commun. 2000, 30, 1725 .

7. Witzeman, J. S.; Notingham, W. D. J. Org. Chem. 1991, 56, 1713.

8. (a) Yazawa, H.; Tanaka, K.; Kariyane, K. Tetrahedron Lett. 1974, 3995. (b) Blossey, E. C.; Turner, L. M.; Neckers, D. C. Tetrahedron Lett. 1973, 1823.

9. Taber, D. F.; Amedio, J. C. Jr.; Patel Y. K. J. Org. Chem. 1985, 50, 3618,

10. Seebach, D.; Thaler, A.; Blaser, D.; Ko. S. Y. Helv. Chim. Acta 1991, 74, 110.

11. Seebach, D.; Hungerbühler, E.; Naef, R.; Schnurrenberger, D.; Weidmann, B.; Zügger, M. Synthesis 1982, 138.

12. Chavan. S. P.; Zubaidha, P. K.; Dantale, S. W.; Keshavaraja, A.; Ramamswamy, A. V.; Ravindranathan. T. Tetrahedron Lett. 1996, 37, 233.

13. (a) Balaji, B. S.; Sasidharan, M.; Kumar, R.; Chanda, B. Chem. Commun. 1996, 707. (b) Balaji, B. S.; Chanda, B. M. Tetrahedron 1998, 54, 13237. (c) Ponde, D.; Deshpande, V. H.; Bulbule, V, J.; Sudalai, A.; Gajare, A. S. J. Org. Chem. 1998, 63, 1058. (d) Bandgar, B. P.; Uppalla, L. S.; Sadavarte, V. S. Green Chem. 2001, 3, 39. (e) Bandgar, B. P.; Sadavarte, V. S., Uppalla, L. S. J. Chem. Res. (S) 2001, 16. (f) Kumar, P.; Pandey, R. K. Synlett 2000, 251. (g) Christoffers, J.; Onal, N. Eur. J. Org.Chem. 2000, 1633. (h) Jin, T.; Zhang, S.; Li, T. Green Chem. 2002, 32.

14. Chavan, S. P.; Rao, T. S.; Dantale, S. W.; Sivappa, R. Synth. Commun. 2001, 31, 289.

15. (a) Chavan, S. P.; Shivasankar, K.; Sivappa, R.; Kale, R. R. Tetrahedron Lett. 2002, 43, 8583. (b) Chavan, S. P.; Kale, R. R.; Shivasankar, K.; Chandake, S, I.; Benjamin, S, B. Synthesis 2003, 2695. (c) Bo, W.; Ming, Y. L.; Shuan, S. J. Tetrahedron Lett. 2003, 44, 5037.

16. Chavan, S. P.; Anand, R.; Pasupathy, K.; Rao, B. S. Green Chem. 2001, 320.

17. (a) The structural detail of this zeolite is available on the World Wide Web (http://www.izastructure.org). (b) Ahedi, R. K.; Kotasthane, A. N. J. Porous Mater. 1997, 4, 171. (c) Donk, S.V.; Bus, E.; Broersma, A.; Bitter, J. H.; Jong, K. P. Appl. Catal. A Gen. 2002, 237, 149 and references cited therein. (d) Domokos, L.; Lefferts, L.; Seshan, K.; Lercher, J. A. J. Mol. Catal. A 2000, 162, 147 and refernces cited therein.

18. (a) Carrol F. M. J. Am. Chem. Soc. 1940, 704. (b) Kimel, W.; Cope, A. C. J. Am. Chem. Soc. 1943, 65, 1992.

19. Swamer, F. W.; Hauser, C. R. J. Am. Chem. Soc. 1950, 72, 1352.

20. Campbell, D. S.; Lawrie, C. W. Chem. Commun. 1971, 355. 